\author{
Muhammed Fatih Kılıçaslan ${ }^{1, *}$, Yasin Yılmaz ${ }^{2}$, Bekir Akgül2, Hakan Karataş³, Can \\ Doğan Vurdu 4 \\ ${ }^{1}$ Department of Fundamental Sciences and Engineering, Sivas University of Science and Technology, \\ Sivas, Turkey \\ ${ }^{2}$ Department of Aeronautical Engineering, Sivas University of Science and Technology, Sivas, Turkey \\ ${ }^{3}$ Department of Materials Sciences and Engineering, Kastamonu University, Kastamonu, Turkey \\ ${ }^{4}$ Department of Biomedical Engineering, Kastamonu University, Kastamonu, Turkey \\ *fatihkilicaslan@sivas.edu.tr
}

\title{
EFFECT OF Fe-Ni SUBSTITUTION IN FeNiSiB SOFT MAGNETIC ALLOYS PRODUCED BY MELT SPINNING
}

\begin{abstract}
Alloys of FeNiSiB soft magnetic materials containing variable Fe and Ni contents (wt.\%) have been produced by melt spinning method, a kind of rapid solidification technique. The magnetic and structural properties of FeNiSiB alloys with soft magnetic properties were investigated by increasing the Fe ratio. X-ray diffraction analysis and SEM images shows that the produced alloy ribbons generally have an amorphous structure, together with also partially nanocrystalline regions. It was observed that the structure became much more amorphous together with increasing $\mathrm{Fe}$ content in the composition. Among the alloy ribbons, the highest saturation magnetization was obtained as $0.6 \mathrm{emu} / \mathrm{g}$ in the specimen with $50 \mathrm{wt} \%$ Fe. In addition, the highest Curie temperature was observed in the sample containing 46 wt. $\%$ Fe.
\end{abstract}

Keywords: Alloy design; Curie temperature; FeNiSiB alloys; melt spinning; saturation magnetization

\section{INTRODUCTION}

Amorphous materials show significantly different physical and chemical properties compared to their crystalline counterparts. This is due to their disordered and metastable short-range atomic arrangement. In fact, such materials have excellent mechanical and physical properties such as high strength [1], high hardness and superior corrosion resistance [2-5]. Additionally, iron-nickel based amorphous alloys lacking of crystalline structure exhibit superior soft magnetic properties including high saturation magnetic flux density $\left(\mathrm{B}_{\mathrm{s}}\right)$, low coercivity $\left(\mathrm{H}_{\mathrm{c}}\right)$, high magnetic susceptibility $(\chi)$ [6]. Thanks to their excellent magnetic properties and other superior mechanical properties, Fe-Ni based amorphous alloys find various applications in critical industrial areas such as power transformers and magnetic sensors $[2,7,8]$. The first production of amorphous materials was carried out by P. Duwez et al., about 60 years ago, by rapidly cooling of the molten alloy by quenching [9]. Duwez's work has been accepted by many researchers. In order to save energy and further 
miniaturization in electromagnetic devices, many researchers have conducted serious studies in this field to enhance materials having high $B_{s}$ and excellent magnetic softness [10-12]. It is known that cooling rates higher than $10^{5} \mathrm{~K} / \mathrm{s}$ are needed for occurrence of amorphous regions in the microstructure of iron, cobalt and nickel based amorphous alloys discovered before the 1990s [3,13]. The strength and hardness of the amorphous alloys at room temperature are higher than their crystalline counterparts with the same chemical composition; this is related to lack of dislocation, grain boundaries and other crystalline defects [14]. Generally, although there are certain methods for the production of the amorphous alloys, rapid solidification process (RSP) [15-17] and mechanical alloying (MA) are known to give more effective results than others [18].

It has become easier to obtain amorphous structures by means of melt spinning method, which is known to be effective and inexpensive among the rapid solidification processes recently. Many researchers doing research on the amorphous structures have preferred using the melt spinning method [12,19-21]. It is possible to produce the amorphous and/or nanocrystalline ribbons with a thickness of about $20-50 \mu \mathrm{m}$ by cooling the molten alloy at cooling rates in range of $10^{6}-10^{9} \mathrm{~K} / \mathrm{s}$ with melt spinning process [5]. Molten metal alloy is sprayed onto the surface of rotating cold copper disc and loses its heat rapidly. As a result, unlike a controlled cooling, the molten metal alloy, which cannot find enough time to crystallize, solidifies in an amorphous structure [22,23].

It is seen that the researchers have intensively discussed many different material groups with iron-based soft magnetic properties [24-27]. Thus, they revealed that the amorphous or nanocrystalline structures exhibit superior properties than their conventional crystalline counterparts. Luciano et al., showed that metallic glass FeSiB alloy outperforms silicon steel in 1997 [28]. In the following years, $\mathrm{FeSiBNbCu}$ alloy, which is known by the trade name FINEMET, was developed [29,30]. However, it is known that expensive and hard-to-find rare elements such as $\mathrm{Nb}$ in this alloy increase the price of the material. Wang et al., examined the magnetic properties of FeNiSiN alloys and showed that they are superior to FINEMET alloy on their study in 2019 [31]. The saturation magnetization value $\left(\mathrm{M}_{\mathrm{s}}\right)$ obtained by Wang was higher than the FINEMET. As can be seen, many researchers in the literature have carried out different studies to improve the magnetic and mechanical properties and reduce the cost of commercially used soft magnetic materials.

On the other hand, another important issue is that the ribbons are amorphous throughout their thickness. Accordingly, whether the structure can be completely or partially amorphous depends on several parameters such as the cooling rate of the molten alloy and distance of nozzle to the copper disc [32]. For example, it has been demonstrated by many researchers that the structure is completely amorphous on the surface of the ribbon in contact with the copper disc, but a certain part of its outer surface crystallizes [24,29,31]. Reason for this is that the heat transfer on the surface of the copper disc is faster than in the air [33]. Rotational speed of the copper disc is one of important parameters affecting the cooling rate [34]. In other words, the rotational speed of the copper disc plays a critical role in formation of the amorphous structure.

In this study, the Fe-Ni based soft magnetic alloy ribbons were produced by using the melt spinning method. Changes in the magnetic and the crystalline structure were investigated by adding Fe element to the alloy instead of $\mathrm{Ni}$, which is relatively expensive in the alloy composition. Thus, it is aimed to reduce costs by enhancing soft magnetic alloys by means of the melt spinning method. In the study, $\mathrm{Fe}_{50} \mathrm{Ni}_{42} \mathrm{Si}_{6} \mathrm{~B}_{2}$ alloy showed the best magnetic property and the saturation magnetization was as high as $0.6 \mathrm{emu} / \mathrm{g}$. Therefore, the $\mathrm{Fe}_{50} \mathrm{Ni}_{42} \mathrm{Si}_{6} \mathrm{~B}_{2}$ alloy can be nominated as a cheap candidate for use in applications such as the soft magnetic power transformers and the magnetic sensors. 


\section{MATERIALS AND METHODS}

Chemical composition of the alloys studied within scope of the study is given in Table 1. The alloys whose compositions were determined within scope of the study were first melted twice in a high-frequency vacuum induction furnace to be more homogeneous. Before starting melting process, the furnace atmosphere was reduced to a vacuum level of $10^{-4}$ mbar twice, and inside of the furnace was cleaned of harmful gases such as oxygen and finally $500 \mathrm{~g}$ of ingot was produced by the melting in a high purity argon atmosphere. For production of the alloys, alloying elements of $\mathrm{Fe}$ ( $99.98 \%$ purity), $\mathrm{Si}$ (99.99\% purity), $\mathrm{Ni}$ ( $99.97 \%$ purity) and $\mathrm{B}$ (95\% purity) procured from Alfa Aesar were used.

A visual summarizing the experimental work done is given in Fig. 1. Accordingly, ingots produced in an appropriate composition were melted again under the argon atmosphere by the melt spinning method and sprayed on the copper disc. The molten metal was sprayed by means of the $0.5 \mathrm{~mm}$ thick nozzles, onto the copper disc rotating at $25 \mathrm{~m} / \mathrm{s}$ with the $400 \mathrm{mbar}$ argon pressure [35]. A ribbon of approximately $10 \mathrm{~mm}$ width and $25 \mu \mathrm{m}$ thickness was produced.
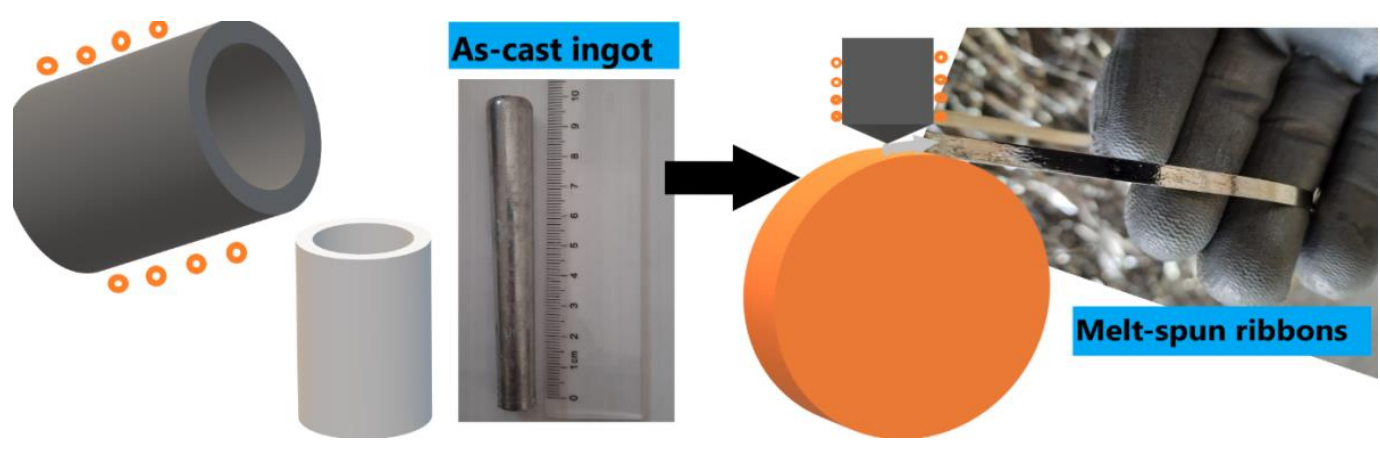

Fig. 1. Schematic of the production process for the ingots and the ribbons

In X-ray diffraction (XRD) (Bruker D8) analyzes, graphite monochromator and high energy $\mathrm{Cu}-\mathrm{K} \alpha$ radiation $\left(\lambda=1.5406 \AA\right.$ ) were used and the $2 \theta$ angle was kept between $3^{\circ}$ and $90^{\circ}$ for measurements. Magnetic saturation analyzes (VSM, LAKE SHORE 7407) were applied under $500 \mathrm{kA} / \mathrm{m}$ magnetic field. Curie temperature determination tests were checked by means of a vibrating sample magnetometer (VSM, LAKE SHORE 7407) under the argon atmosphere at a speed of $2.5^{\circ} \mathrm{C} / \mathrm{s}$ under $4 \mathrm{kA} / \mathrm{m}$ magnetic field. In addition, SEM and EDX mapping analyzes were performed on the TESCAN MIRA 3 brand device. In this way, the homogeneous distribution of alloying elements in the samples, the thickness of the ribbons and whether microcrystals were formed or not $[36,37]$.

\section{RESULTS AND DISCUSSION}

In Fig. 2, the X-ray diffraction (XRD) patterns of the alloy ribbons of F1, F2 and F3 by the melt-spinning of Fe-Ni-based alloys having soft magnetic properties are shown. As can be seen, from the XRD analysis of each alloy, it is seen that the alloys are generally in amorphous structures and also partial nanocrystalline phases are obtained within these 
amorphous structures. Accordingly, a distinct sharp Bragg peak is observed at $2 \Theta=44^{\circ}$ in the XRD pattern representing alloy $\mathrm{F} 1\left(\mathrm{Fe}_{42} \mathrm{Ni}_{50} \mathrm{Si}_{6} \mathrm{~B}_{2}\right)$.

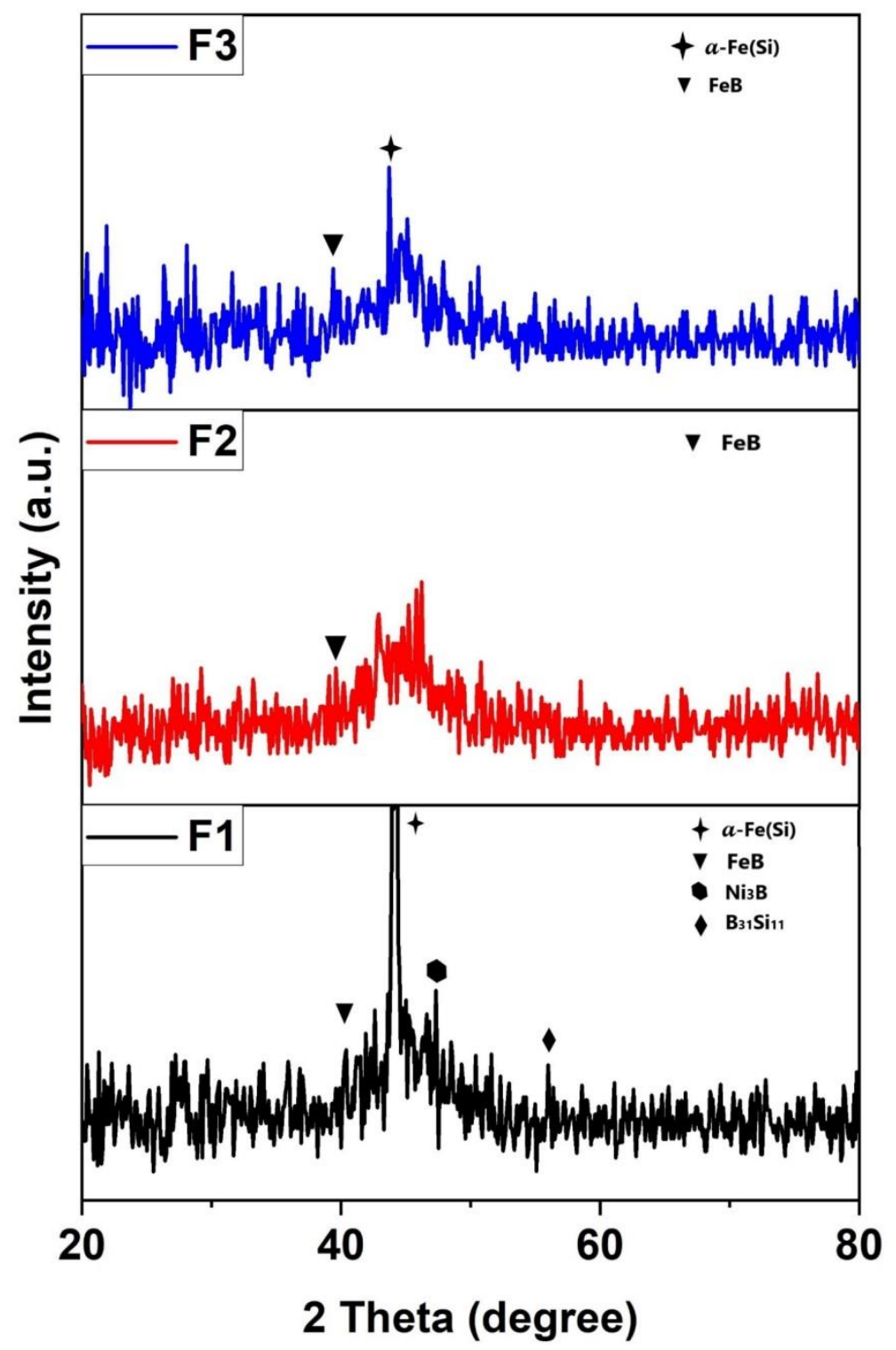

Fig. 2. The XRD patterns for the alloy ribbons of F1 (black), F2 (red) and F3 (blue) produced by the melt spinning

This indicates that the specimen is partially crystallized. It has been determined that the alloy $\mathrm{F} 1$ is generally amorphous, but peaks of orthorhombic $\mathrm{FeB}, \mathrm{Ni}_{3} \mathrm{~B}$ and rhombohedral $\mathrm{B}_{31} \mathrm{Si}_{11}$ nanocrystalline intermetallic phases with high melting point are also observed. The XRD results obtained in the alloy F1 agree with Wang's work in 2019 [31]. No sharp Bragg diffraction peaks were observed in the XRD patterns representing alloys $\mathrm{F} 2\left(\mathrm{Fe}_{46} \mathrm{Ni}_{46} \mathrm{Si}_{6} \mathrm{~B}_{2}\right)$ and $\mathrm{F} 3\left(\mathrm{Fe}_{50} \mathrm{Ni}_{42} \mathrm{Si}_{6} \mathrm{~B}_{2}\right)$. The XRD peak, which is sharp in the alloy coded as $\mathrm{F} 1$ at approximately $2 \Theta=44^{\circ}$, has a diffuse characteristic in the alloys F2 and F3. According to these results, it is seen that the alloys F2 and F3 are mostly amorphous. In the XRD pattern representing the alloy coded as $\mathrm{F} 3, \mathrm{Fe}_{2} \mathrm{Si}$ nanocrystalline intermetallic phase is encountered at approximately $2 \Theta=44^{\circ}$. It was determined that intensity of the peak of $\mathrm{FeB}$ nanocrystalline phase increased due to increase in the amount of $\mathrm{Fe}$ and decrease in the amount of $\mathrm{Ni}$ in the alloys F3 compared to the alloy F2. In the study of Jia et al. in 2020, amorphous forming ability (AFA) of the alloys increased with increase of the Ni content in the range of $0-20 \%$ by 
weight [10]. However, in our study, a different result was obtained because the amount of $\mathrm{Ni}$ was quite high. According to the obtained results, it is seen that the AFA of the alloy increases with the substitution of the Ni by Fe in the alloy composition and almost the entire structure turns into amorphous. The reason of this, it is thought that it may be caused by similarity in atomic packing of Fe and Ni elements, whose atomic radius are $1.26 \AA$ and 1.24 $\AA$, respectively. Atomic size differences do not change much, with replacement of the $\mathrm{Ni}$ and Fe elements in the alloy. On the other hand, it is known that the atomic size differences affect crystallization process [38]. According to Inoue, in order to obtain an amorphous structure in the alloy composition, the atomic size difference between the elements forming the alloy should be above $12 \mathrm{wt} . \%$ [39-41]. In addition, it has been proven in previous studies that $\mathrm{Si}$ atoms in magnetic alloys play a supporting role in forming the amorphous structure [39,42]. Although atomic radii of the $\mathrm{Fe}$ and $\mathrm{Ni}$ elements are close, it can be said that amorphous forming ability (AFA) of the Fe element with the Si element is slightly better. Also, it is known that the B element used in the alloy improves the AFA, like the C element $[41,43]$. This is explained by similar atomic radius $(0.85 \AA$ and $0.86 \AA$, respectively), valences, and electronegativity of the $\mathrm{B}$ and $\mathrm{C}$ elements $[39,44]$. It is thought that with replacement of the Ni element with the Fe element, the atomic size difference increases a little more and the AFA ability increases.

Fig. 3 shows the M-H measurement results and typical hysteresis curves of the alloy ribbons of F1, F2 and F3 by the melt spinning made via vibrating sample magnetometer (VSM) analysis of the soft magnetic ribbons of three different compositions. Accordingly, the highest saturation magnetization value was observed in the alloy F3. Increase in the amount of Fe significantly affected the saturation magnetization $\left(\mathrm{M}_{\mathrm{s}}\right)$ value of the alloy, and the $\mathrm{M}_{\mathrm{s}}$ value increased from $0.4 \mathrm{emu} / \mathrm{g}$ to $0.6 \mathrm{emu} / \mathrm{g}$. Depending on the increase in Fe content in the alloy composition, the soft magnetic property of the material increased significantly. This situation can be explained by the following mechanism: Based on the energy band theory, magnetic moment of the $\mathrm{Fe}$ atom is $2.2 \mu \mathrm{B}$, and the magnetic moment of the $\mathrm{Ni}$ atom is 0.6 $\mu \mathrm{B}$. Hence, it is thought that replacement of the $\mathrm{Ni}$ atom by the $\mathrm{Fe}$ atom in the alloy composition will increase the saturation magnetization value of the alloy $[32,45,46]$. From the inset hysteresis curve in Fig. 3, coercivity values of the soft magnetic alloy ribbons were calculated as $3.0 \mathrm{~A} / \mathrm{m}, 4.1 \mathrm{~A} / \mathrm{m}$ and $3.1 \mathrm{~A} / \mathrm{m}$ for the alloy ribbons of $\mathrm{F} 1, \mathrm{~F} 2$ and $\mathrm{F} 3$ respectively. Table 1 shows the saturation magnetization $\left(B_{s}\right)$, the magnetic coercivity $\left(H_{c}\right)$ and Curie temperature $\left(\mathrm{T}_{\mathrm{c}}\right)$ values calculated for F1, F2 and F3 samples. As shown in the Table 1 , the $H_{c}$ value slightly increased from $3.0 \mathrm{~A} / \mathrm{m}$ for the alloy $\mathrm{F} 1$ to $4.1 \mathrm{~A} / \mathrm{m}$ for the alloy $\mathrm{F} 2$, with the increase in the Fe content. However, it decreased to $3.1 \mathrm{~A} / \mathrm{m}$ at the $50 \mathrm{wt} \% \mathrm{Fe}$ ratio. These coercivity values are well below the studies in the literature $[32,47]$. Because it is known that annealing process applied to the soft magnetic materials increases the coercivity values $[32,47]$.

Table 1. Magnetic properties of the alloy ribbons of F1, F2 and F3 produced by the melt spinning

\begin{tabular}{lccc}
\hline $\begin{array}{l}\text { Properties/ } \\
\text { Alloys }\end{array}$ & $\begin{array}{c}\text { Saturation Magnetization, } \\
\mathrm{B}_{\mathrm{s}}(\mathrm{emu} / \mathrm{g})\end{array}$ & $\begin{array}{c}\text { Coercivity, } \mathrm{H}_{\mathrm{c}} \\
(\mathrm{A} / \mathrm{m})\end{array}$ & $\begin{array}{c}\text { Curie Temperature, } \mathrm{T}_{\mathrm{c}} \\
(\mathrm{K})\end{array}$ \\
\hline F1 & 0.4 & 3.0 & 700 \\
F2 & 0.3 & 4.1 & 730 \\
F3 & 0.6 & 3.1 & 680 \\
\hline
\end{tabular}




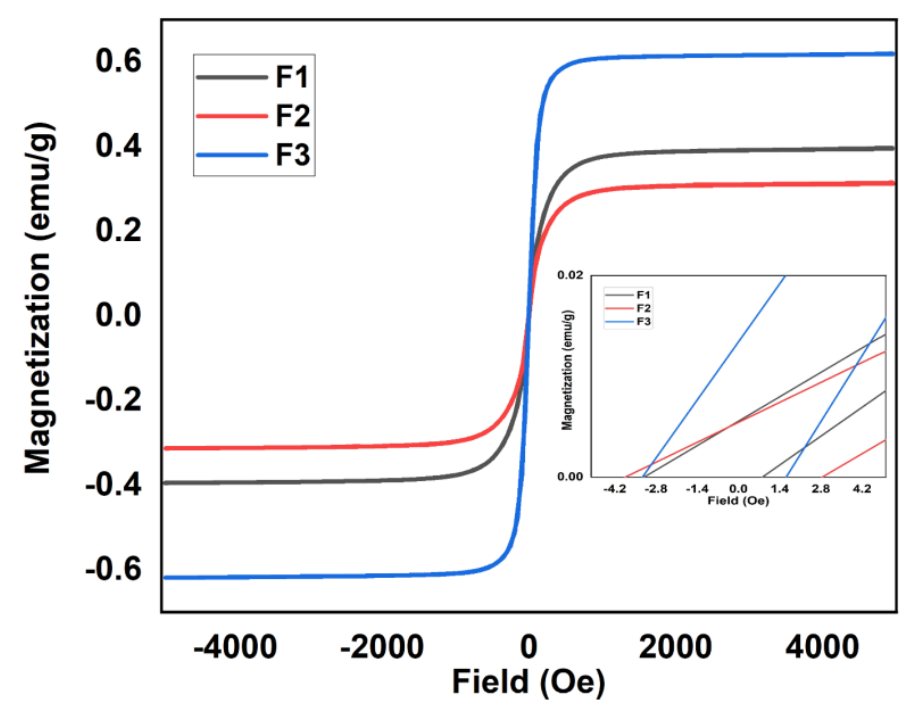

Fig. 3. The magnetization curves of the alloy ribbons of F1 (black), F2 (red) and F3 (blue) produced by the melt spinning

Fig. 4 shows M-T curves of the alloy ribbons of F1, F2 and F3 by the melt spinning, which give variation of the magnetization with the temperature. As seen from the curves, the Curie temperature increased from $700 \mathrm{~K}$ to $730 \mathrm{~K}$ with the increase of the Fe content in the alloy ribbons from $42 \mathrm{wt} . \%$ to $46 \mathrm{wt} . \%$. When the amount of $\mathrm{Fe}$ in the alloy composition rises to $50 \mathrm{wt} . \%$, a decrease to $680 \mathrm{~K}$ was observed in the Curie temperature. This situation can be explained by the following reasons: It is known that exchange interaction of $3 \mathrm{~d}$-electrons affects the $T_{c}$ temperature and is directly related to associated bond electron density [48]. Accordingly, localized electrons in the $3 \mathrm{~d}$-shell can interact only over an atomic distance. However, non-localized electrons in s-shell are known to interact over six atomic distances [49]. Therefore, since the $\mathrm{Fe}$ and $\mathrm{Ni}$ atoms have 6 and 8 electrons in the 3d-band, respectively, the electron exchange here decreases with the increase in Ni content. On the other hand, with the increase in the Ni content, contribution of the s- shell electrons to the $T_{c}$, increases [50]. Consequently, change in the $T_{c}$ is determined by cooperative contribution of the $3 \mathrm{~d}$-electrons and the s-electrons [45]. Effect of the localized or the non-localized electrons in the 3d- and sshells on the magnetic properties was clearly seen. Indeed, the change in the $\mathrm{Fe}$ and $\mathrm{Ni}$ contents has a significant effect on the magnetic properties of the alloys.

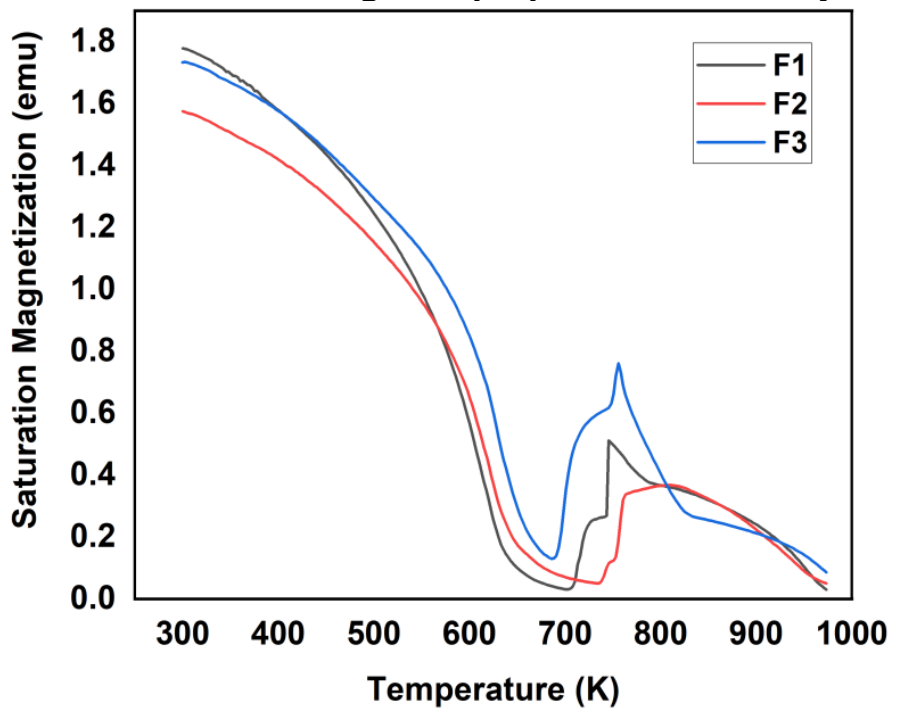

Fig. 4. Thermo-magnetic (T-M) curves of the alloy ribbons of $F 1$ (black), F2 (red) and F3 (blue) produced by the melt spinning 
Figure 5 shows the SEM and EDX mapping analysis results of the samples. It is seen that the ribbons thicknesses vary between about $40-50 \mu \mathrm{m}$. It is seen that our results are compatible with the studies in the literature [18,51]. It is known that the disc rotation speed indirectly affects the strip thickness and cooling rate in order to form an amorphous structure. Therefore, it is understood from both XRD and SEM images that the structure can attain an amorphous form at the disk rotation speed of $25 \mathrm{~m} / \mathrm{s}$ we have chosen. As can be seen from the SEM results in Figure 5, no crystal structure was found. On the other hand, in the EDX maps in Figure 5, it is seen that the elements in the samples show a homogeneous distribution.
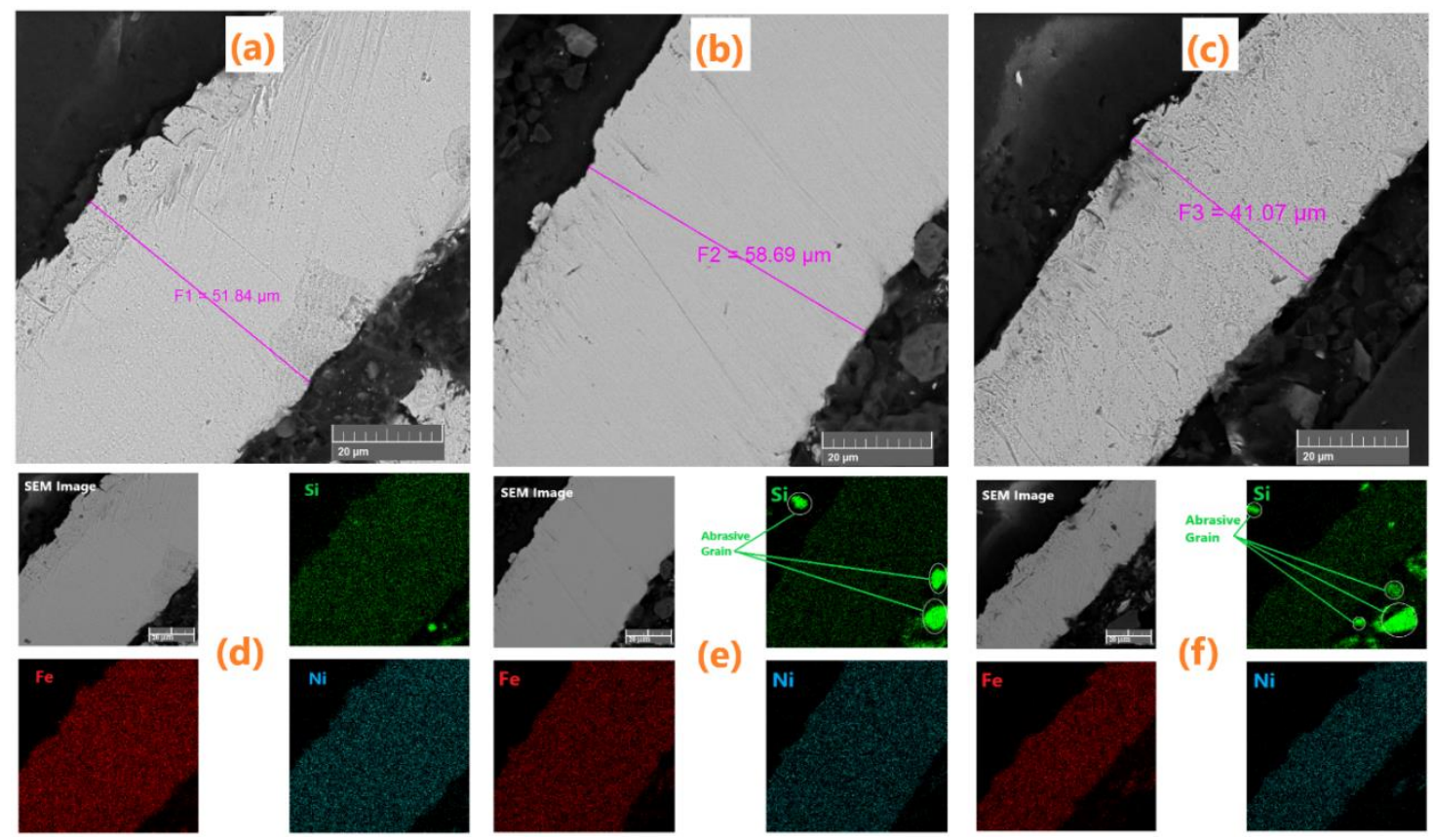

Fig. 5. SEM images (a-c) and EDX Maps (d-f) for melt spun ribbons. (a,d) F1, (b,e) F2, (c,f) F3

\section{CONCLUSIONS}

The soft magnetic alloy ribbons with three different chemical compositions were produced by the melt spinning method, which is one of the rapid solidification methods. According to this;

- In the results of the XRD analysis of the alloy ribbons, it was clearly seen that the structure turned into a much more amorphous form with the increase of the Fe content. Although there are partial nanocrystalline phases in the alloy ribbons with high $\mathrm{Fe}$ content, the structure was found to be substantially amorphous.

- According to the results of the VSM analysis, it was observed that the saturation magnetization increased with the increase of the iron content in the alloy ribbons.

- From the M-T curves of the alloy ribbons, it was observed that the amount of $\mathrm{Fe}$ increases up to $46 \mathrm{wt}$.\% increased the $\mathrm{T}_{\mathrm{c}}$ temperature.

- The magnetic coercivity value slightly increased with the increase of the Fe content up to 46 wt. $\%$.

According to these results, it is thought that increasing the Fe constituent, which is cheaper than $\mathrm{Ni}$, in the $\mathrm{Fe}-\mathrm{Ni}$ soft magnetic materials used in sensitive electrical and electronic components, may be effective in terms of both economic and magnetic properties. 


\section{REFERENCES}

1. I.A. Figueroa, I. Betancourt, G. Lara, J.A. Verduzco, Effect of B, Si and $\mathrm{Cr}$ on the mechanical properties of Fe-based amorphous metallic ribbons, J. Non. Cryst. Solids. 351 (2005) 3075-3080. https://doi.org/10.1016/j.jnoncrysol.2005.07.017.

2. L. Guo, S. Geng, X. Gao, W. Wang, Numerical simulation of heat transfer and fluid flow during nanosecond pulsed laser processing of Fe78Si9B13 amorphous alloys, Int. J. Heat Mass Transf. 170 (2021). https://doi.org/10.1016/j.ijheatmasstransfer.2021.121003.

3. A. Inoue, Stabilization of metallic supercooled liquid and bulk amorphous alloys, Acta Mater. 48 (2000) 279-306. https://doi.org/10.1016/S1359-6454(99)00300-6.

4. S. Cui, H. Zhai, W. Li, X. Fan, X. Li, W. Ning, D. Xiong, Microstructure and corrosion resistance of Fe-based amorphous coating prepared by detonation spray, Surf. Coat. Technol. 399 (2020) 126096. https://doi.org/10.1016/j.surfcoat.2020.126096.

5. M.F. Kilicaslan, S.I. Elburni, B. Akgul, The effects of nb addition on the microstructure and mechanical properties of melt spun Al-7075 alloy, Adv. Mater. Sci. 21 (2021) 17-19. https://doi.org/10.2478/adms-2021-0008.

6. L. Zhu, S.S. Jiang, Z.Z. Yang, G.B. Han, S.S. Yan, Y.G. Wang, Magnetic properties of a Febased amorphous alloy with stress gradient, J. Magn. Magn. Mater. 519 (2021) 167513. https://doi.org/10.1016/j.jmmm.2020.167513.

7. C. Chang, T. Kubota, A. Makino, A. Inoue, Synthesis of ferromagnetic Fe-based bulk glassy alloys in the $\mathrm{Fe}-\mathrm{Si}-\mathrm{B}-\mathrm{P}-\mathrm{C}$ system, J. Alloys Compd. 473 (2009) 368-372. https://doi.org/10.1016/j.jallcom.2008.05.088.

8. A. Makino, H. Men, T. Kubota, K. Yubota, A. Inoue, FeSiBPCu nanocrystalline soft magnetic alloys with high $\mathrm{B}_{\mathrm{s}}$ of 1.9 Tesla produced by crystallizing hetero-amorphous phase, Mater. Trans. 50 (2009) 204-209. https://doi.org/10.2320/matertrans.MER2008306.

9. P. Duwez, R. H. Willens, W. Klement, Continuous Series of Metastable Solid Solutions in Silver Copper Alloys, J. Appl. Phys. 31 (1960) 1136. https://doi.org/10.1063/1.1735777.

10. X. Jia, Y. Li, L. Wu, W. Zhang, A study on the role of Ni content on structure and properties of Fe-Ni-Si-B-P-Cu nanocrystalline alloys, J. Alloys Compd. 822 (2020) 152784. https://doi.org/10.1016/j.jallcom.2019.152784.

11. M. Ohta, Y. Yoshizawa, $\mathrm{Cu}$ addition effect on soft magnetic properties in Fe-Si-B alloy system, J. Appl. Phys. 103 (2008) 07E722. 722 (2015). https://doi.org/10.1063/1.2829240.

12. Y. Zhang, P. Sharma, A. Makino, Effects of cobalt addition in nanocrystalline Fe83.3Si4B8P4Cu0.7 soft magnetic alloy, IEEE Trans. Magn. 50 (2014) 2003004.

13. A. Inoue, A. Takeuchi, T. Zhang, Ferromagnetic bulk amorphous alloys, Metall. Mater. Trans. A Phys. Metall. Mater. Sci. 29 (1998) 1779-1793. https://doi.org/10.1007/s11661-998-0001-9.

14. C. Si, Z. Zhang, Q. Zhang, J. Cai, Influence of mechanical alloying on the particle size, microstructure and soft magnetic properties of coarse Fe-based amorphous powders prepared by gas atomization, J. Non. Cryst. Solids. $559 \quad$ (2021) 120675. https://doi.org/10.1016/j.jnoncrysol.2021.120675.

15. S. Cui, G. Ouyang, T. Ma, C. R. Macziewski, V. I. Levitas, L. Zhou, M. J. Kramer, J. Cui, Thermodynamic and kinetic analysis of the melt spinning process of $\mathrm{Fe}-6.5 \mathrm{wt} . \% \mathrm{Si}$ alloy, J. Alloys Compd. 771 (2019) 643-648. https://doi.org/10.1016/J.JALLCOM.2018.08.293.

16. Y.F. Liang, S. Wang, H. Li, Y.M. Jiang, F. Ye, J. P. Lin, Fabrication of Fe-6.5wt\%Si Ribbons by Melt Spinning Method on Large Scale, Adv. Mater. Sci. Eng. 2015 (2015). 
https://doi.org/10.1155/2015/296197.

17. S. Wang, Y. M. Jiang, Y. F. Liang, F. Ye, J. P. Lin, Magnetic properties and core loss behavior of Fe-6.5wt.\% Si ribbons prepared by melt spinning, Adv. Mater. Sci. Eng. 2015 (2015). https://doi.org/10.1155/2015/410830.

18. M. Imani, M. H. Enayati, Investigation of amorphous phase formation in Fe-Co-Si-B-PThermodynamic analysis and comparison between mechanical alloying and rapid solidification $\begin{array}{llllll}\text { experiments, J. } & \text { Jlloys } & \text { Compd. } & & \end{array}$ https://doi.org/10.1016/j.jallcom.2017.02.100.

19. A. Inoue, T. Masumoto, Mg-based amorphous alloys, Mater. Sci. Eng. A. 173 (1993) 1-8. https://doi.org/10.1016/0921-5093(93)90175-E.

20. T. Tamura, M. Li, Influencing factors on the amorphous phase formation in $\mathrm{Fe}-7.7$ at $\% \mathrm{Sm}$ alloys solidified by high-speed melt spinning, J. Alloys Compd. $826 \quad$ (2020) 154010. https://doi.org/10.1016/j.jallcom.2020.154010.

21. G. Ennas, M. Magini, F. Padella, P. Susini, G. Boffitto, G. Licheri, Preparation of amorphous Fe$\mathrm{Zr}$ alloys by mechanical alloying and melt spinning methods - Part 1 A structural comparison, J. Mater. Sci. 24 (1989) 3053-3058. https://doi.org/10.1007/BF01139017.

22. C. Wu, K. Lin, Y. Cheng, C. Huang, C. Pan, W. Li, L. Chiang, C. Yeh, S. Fong, Development of Amorphous Ribbon Manufacturing Technology, China Steel Tech. Rep. (2014) 28-42.

23. G. Herzer, Modern soft magnets: Amorphous and nanocrystalline materials, Acta Mater. 61 (2013) 718-734. https://doi.org/10.1016/j.actamat.2012.10.040.

24. X. D. Fan, B.L. Shen, Crystallization behavior and magnetic properties in High Fe content $\mathrm{FeBCSiCu}$ alloy system, J. Magn. Magn. Mater. 385 (2015) 277-281. https://doi.org/10.1016/j.jmmm.2015.03.033.

25. N. Yodoshi, S. Ookawa, R. Yamada, N. Nomura, K. Kikuchi, A. Kawasaki, Effects of nanocrystallisation on saturation magnetisation of amorphous Fe76Si9B10P5, Mater. Res. Lett. 6 (2018) 100-105. https://doi.org/10.1080/21663831.2017.1398191.

26. K. Suzuki, R. Parsons, B. Zang, K. Onodera, H. Kishimoto, T. Shoji, A. Kato, Nanocrystallization of amorphous alloys by ultra-rapid annealing: An effective approach to magnetic softening, J. Alloys Compd. 735 (2018) 613-618. https://doi.org/10.1016/j.jallcom.2017.11.110.

27. T. Kulik, Nanocrystallization of metallic glasses, J. Non. Cryst. Solids. 287 (2001) 145-161. https://doi.org/10.1016/S0022-3093(01)00627-5.

28. B. A. Luciano, C. S. Kiminami, An amorphous core transformer: Design and experimental performance, Mater. Sci. Eng. A. 226-228 (1997) 1079-1082. https://doi.org/10.1016/s09215093(96)10863-7.

29. F. Wan, T. Liu, F. Kong, A. Wang, M. Tian, J. Song, J. Zhang, C. Chang, X. Wang, Surface crystallization and magnetic properties of $\mathrm{FeCuSiBNbMo}$ melt-spun nanocrystalline alloys, Mater. Res. Bull. 96 (2017) 275-280. https://doi.org/10.1016/j.materresbull.2017.01.026.

30. Y. Yoshizawa, S. Oguma, K. Yamauchi, New Fe-based soft magnetic alloys composed of ultrafine grain structure, J. Appl. Phys. 64 (1988) 6044-6046. https://doi.org/10.1063/1.342149.

31. J. G. Wang, H. Zhao, C. X. Xie, C. T. Chang, S. M. Zhou, J. Q. Feng, J. T. Huo, W. H. Li, In-situ synthesis of nanocrystalline soft magnetic Fe-Ni-Si-B alloy, J. Alloys Compd. 790 (2019) 524528. https://doi.org/10.1016/j.jallcom.2019.03.226.

32. E. Dastanpour, M. H. Enayati, A. Masood, V. Ström, Crystallization behavior, soft magnetism and nanoindentation of Fe-Si-B-P-Cu alloy on Ni substitution, J. Alloys Compd. 851 (2021) 156727. https://doi.org/10.1016/j.jallcom.2020.156727. 
33. Z. Li, Y. Wu, B. Zhuang, X. Zhao, Y. Tang, X. Ding, Preparation of novel copper-powdersintered frame / para ffi $\mathrm{n}$ form-stable phase change materials with extremely high thermal $\begin{array}{lllll}\text { conductivity, } & \text { Appl. } & \text { Energy. } & 206 & \text { (2017) }\end{array}$ https://doi.org/10.1016/j.apenergy.2017.10.046.

34. V. I. Tkatch, A. I. Limanovskii, S. N. Denisenko, S. G. Rassolov, The effect of the melt-spinning processing parameters on the rate of cooling, Mater. Sci. Eng. A. 323 (2002) 91-96. https://doi.org/10.1016/S0921-5093(01)01346-6.

35. O. Uzun, M. F. Kılıçaslan, F. Yılmaz, Formation of novel flower-like silicon phases and evaluation of mechanical properties of hypereutectic melt-spun $\mathrm{Al}-20 \mathrm{Si}-5 \mathrm{Fe}$ alloys with addition of V, Mater. Sci. Eng. A. 607 (2014) 368-375. https://doi.org/10.1016/j.msea.2014.04.025.

36. M. Çelebi, O. Güler, A. Çanakçı, H. Çuvalcı, The effect of nanoparticle content on the microstructure and mechanical properties of ZA27-Al2O3-Gr hybrid nanocomposites produced by powder metallurgy, J. Compos. Mater. 55 (2021) 3395-3408. https://doi.org/10.1177/00219983211015719.

37. A. H. Karabacak, A. Çanakçı, F. Erdemir, S. Özkaya, M. Çelebi, Effect of different reinforcement on the microstructure and mechanical properties of AA2024-based metal matrix nanocomposites, Int. J. Mater. Res. 111 (2020) 416-423. https://doi.org/10.3139/146.111901.

38. A. Inoue, Stabilization of metallic supercooled liquid and bulk amorphous alloys, Acta Mater. 48 (2000) 279-306. https://doi.org/10.1016/S1359-6454(99)00300-6.

39. Y. L. Li, Z. X. Dou, X. M. Chen, K. Lv, F. S. Li, X.D. Hui, Improving the amorphous forming ability and magnetic properties of $\mathrm{FeSiBPCu}$ amorphous and nanocrystalline alloys by utilizing carbon, J. Alloys Compd. 844 (2020). https://doi.org/10.1016/j.jallcom.2020.155767.

40. A. Inoue, A. Takeuchi, T. Zhang, A. Murakami, Soft Magnetic Properties of Bulk Fe-Based Amorphous Alloys Prepared by Copper Mold Casting, IEEE Trans. Magn. 32 (1996) 4866-4871.

41. A. Takeuchi, A. Inoue, Classification of Bulk Metallic Glasses by Atomic Size Difference, Heat of Mixing and Period of Constituent Elements and Its Application to Characterization of the Main $\begin{array}{llllll}\text { Alloying } & \text { Element, } & \text { Mater. } & \text { Trans. } & 46 & \text { (2005) }\end{array}$ https://doi.org/10.2320/matertrans.46.2817.

42. M. Ipatov, V. Zhukova, L. Dominguez, K.L. Alvarez, A. Chizhik, A. Zhukov, J. Gonzalez, Structural and low-temperature magnetic properties of as-quenched and annealed $\mathrm{Ni}-\mathrm{Si}-\mathrm{B}$ alloys produced by rapid solidification, Intermetallics. $132 \quad$ (2021) 107140. https://doi.org/10.1016/j.intermet.2021.107140.

43. B. Q. Chi, C. Li, Z.H. Huang, Mixing entropy difference between liquid and crystal of Fe base amorphous alloys, J Non Cryst Solids. 402 (2014) 178-181. https://doi.org/10.1016/j.jnoncrysol.2014.05.032.

44. L. Shi, X. Qin, K. Yao, Tailoring soft magnetic properties of Fe-based amorphous alloys through C addition, Prog. Nat. Sci. Mater. Int. 30 (2020) 208-212. https://doi.org/10.1016/j.pnsc.2020.02.001.

45. Q. Liu, H. Liu, M. Wang, Y. Zhang, Z. Ma, Y. Zhao, W. Yang, Effects of Ni substitution for Fe on magnetic properties of $\mathrm{Fe}_{80}{ }_{-} \mathrm{Ni}_{x} \mathrm{P}_{13} \mathrm{C}_{7}(\mathrm{x}=0-30)$ glassy ribbons, J. Non. Cryst. Solids. 463 (2017) 68-71. https://doi.org/10.1016/j.jnoncrysol.2017.03.005.

46. J. Zhou, W. Yang, C. Yuan, B. Sun, B. Shen, Ductile FeNi-based bulk metallic glasses with high strength and excellent soft magnetic properties, J. Alloys Compd. 742 (2018) 318-324. https://doi.org/10.1016/j.jallcom.2018.01.317.

47. H. R. Lashgari, D. Chu, S. Xie, H. Sun, M. Ferry, S. Li, Composition dependence of the microstructure and soft magnetic properties of Fe-based amorphous/nanocrystalline alloys: A review study, J. Non-Cryst. Solids. 391 (2014) 61-82. 
https://doi.org/10.1016/j.jnoncrysol.2014.03.010.

48. T. Mizoguchi, K. Yamauchi, H. Miyajima, Ferromagnetism of Amorphous Iron Alloys. Proceedings of the International Symposium on Amorphous Magnetism, Detroit, Michigan, USA, 1973, 325-330. https://doi.org/10.1007/978-1-4613-4568-8_35.

49. W. Yang, H. Liu, L. Xue, J. Li, C. Dun, J. Zhang, Magnetic properties of $\left(\mathrm{Fe}_{1-x} \mathrm{Nix}_{72} \mathrm{~B}_{20} \mathrm{Si}_{4} \mathrm{Nb}_{4}\right.$ $(\mathrm{x}=0.0-0.5)$ bulk metallic glasses, J. Magn. Magn. Mater. 335 (2013) 172-176. https://doi.org/10.1016/j.jmmm.2013.02.004.

50. W. Yang, H. Liu, Y. Zhao, A. Inoue, K. Jiang, J. Huo, H. Ling, Q. Li, B. Shen, Mechanical properties and structural features of novel Fe-based bulk metallic glasses with unprecedented plasticity, Sci. Rep. 6233 (2014) 1-6. https://doi.org/10.1038/srep06233.

51. A. Mitra, R.K. Roy, B. Mahato, A.K. Panda, G. Vlasak, D. Janickovic, P. Svec, Development of $\mathrm{FeSiB} / \mathrm{CoSiB}$ Bilayered Melt-spun Ribbon by Melt-spinning Technique, J. Supercond. Nov. Magn. 2010 241. 24 (2010) 611-615. https://doi.org/10.1007/S10948-010-0955-X. 